Research Paper:

\title{
The Role of Mental Health of Mothers of Children With Learning Disabilities in the Relationship Between Paren- tal Stress, Mother-child Interaction, and Children's Be- havioral Disorders
}

\author{
Setareh Mohammadipour ${ }^{1}$ (D) ${\text { Zahra Dasht Bozorgi }{ }^{1 *} \text { (D), Farzaneh Hooman }}^{1}$ (i)
}

1. Department of Psychology, Ahvaz Branch, Islamic Azad University, Ahvaz, Iran.

\begin{tabular}{|c|c|}
\hline $\begin{array}{l}\text { Use your device to scan } \\
\text { and read the article online }\end{array}$ & dettion: Mohammadipour, S., Dasht Bozorgi, Z., \& Hooman, F. 2021. The Role of Mental Health of Mothers of Children \\
\hline 口ptpra & With Learning Disabilities in the Relationship Between Parental Stress, Mother-child Interaction, and Children's Behavioral \\
\hline$+1 x^{2}$ & Disorders. Journal of Client-Centered Nursing Care, 7(2), pp. 149-158. https://doi.org/10.32598/JCCNC.7.2.362.1 \\
\hline afteris & dol'https://doi.org/10.32598/JCCNC.7.2.362.1 \\
\hline
\end{tabular}

\section{(1) (9)}

Article info:

Received: 01 Jan 2021

Accepted: 25 Mar 2021

Published: 01 May 2021
Keywords:

Learning disabilities, Behavior, Parents, Stress, Mental health, Children

\section{A B S T RA C T}

Background: Behavioral problems of children are common and debilitating conditions that create many difficulties for both children and their families. The present study aimed to investigate the relationship between parental stress and mother-child interaction, and children's behavioral disorders with the mediating role of mental health in the mothers of children with learning disabilities.

Methods: The research population of this descriptive-correlational study consisted of the mothers of all students with learning disabilities in Andimeshk City, Iran, in 2020. Applying the convenience sampling method, 210 students were selected as the study sample. The research instruments included the Child Behavior Checklist, the Parental Stress Scale, the Child-Parent Relationship Scale, and the Symptom Checklist (SCL-25). The proposed model was evaluated using path analysis in AMOS v. 24.

Results: The obtained results indicated a direct and significant relationship between parental stress and children's behavioral disorders $(\beta=0.321, \mathrm{P}=0.0001)$, as well as mother-child interaction and mothers' mental health $(\beta=0.255, \mathrm{P}=0.001)$. There was a negative relationship between mother-child interaction and children's behavioral disorders $(\beta=-0.148, \mathrm{P}=0.019)$, as well as parental stress and mothers' mental health $(\beta=-0.581, \mathrm{P}=0.0001)$. Furthermore, the collected results presented a reverse and significant relationship between mothers' mental health and children's behavioral disorders $(\beta=-0.360, \mathrm{P}=0.0001)$. The indirect path analysis data revealed that mothers' mental health played a mediating role in the relationship between parental stress, mother-child interaction, and children's behavioral disorders $(\mathrm{P}=0.001)$.

Conclusion: According to the present research results, the model proposed in this study was favorably fitted; thus, it can be considered as an important step in identifying the factors affecting behavioral disorders in students with learning disabilities.

\footnotetext{
*Corresponding Author:
}

Zahra Dasht Bozorgi, PhD.

Address: Department of Psychology, Ahvaz Branch, Islamic Azad University, Ahvaz, Iran

Tel: +98 (61) 33329200

E-mail: zdashtbzrgi@gmail.com 


\section{Highlights}

- There was a direct and significant relationship between maternal stress and children's behavioral disorders.

- There was a direct and significant relationship between mother-child interaction and mothers' mental health.

- There was a negative relationship between maternal stress and mothers' mental health.

- Maternal mental health played a mediating role in the relationship between mother-child interaction and children's behavioral disorders.

\section{Plain Language Summary}

Behavioral problems of children are common and debilitating conditions that cause many difficulties for children and their families. Accordingly, these conditions lead to helplessness and reduced self-efficacy and affect children's personal and academic performance. The mothers of students with learning disabilities usually report extensive negative consequences of psychological wellbeing problems as soon as they notice their child's problems. In general, this study suggested the following conclusions: there was a direct relationship between mothers' stress and children's behavioral disorders, as well as mother-child interaction and the mental health of the mothers of children with learning disabilities. There was a negative relationship between mother-child interaction and children's behavioral disorders, as well as parental stress and the mental health of the mothers. The mental health of the mothers played a mediating role in the relationship between mother-child interaction and children's behavioral disorders, as well as parental stress and children's behavioral disorders.

\section{Introduction}

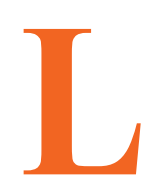

earning disability is defined as insufficient academic achievement of the learner concerning age, Intelligence Quotient (IQ), the type of education or standard reading, writing, and arithmetic tests (Kohli et al. 2018). The term learning disability does not merely refer to special-needs children; it addresses the need to identify and assist students who consistently face academic failures (Sahu et al. 2018). Learning disabilities account for 5\%-15\% of the learner population with a higher prevalence in males (Holt \& Yuill 2017). Students with learning disabilities have a normal appearance, weight, and height; almost a normal IQ; and the ability to easily talk, play, and communicate with others, like their peers; however, they cannot process information to talk and write (Panicker \& Chelliah 2016). Such students present disabilities in one or more psychological processes related to spoken or written comprehension; accordingly, it may manifest as a complete inability to listen, speak, read, write, spell, or perform mathematical calculations (Gow, Mostert \& Dreyer 2020; Vidyadharan \& Tharayil 2019).

Children with learning disabilities cannot control themselves and the surrounding environment; thus, they usu- ally fail to achieve their desires or be noticed by others (Benner et al. 2013). As a result, they may exhibit some symptoms of behavioral disorders, various extreme, chronic, and deviant behaviors that range from aggression or sudden arousal to depression and isolation. Behavioral problems of children are common and debilitating conditions that cause numerous difficulties for the affected children and their families; thus, they lead to helplessness and reduced self-efficacy and affect children's personal and academic performance (Ogundele 2018). Some of the common behavioral disorders in children are hyperactivity, aggression, anxiety, depression, social maladaptation, fear, and conduct disorder; all of which require early diagnosis and intervention (Kivumbi et al. 2019).

Approximately 14\%-24\% of children and adolescents encounter various behavioral and emotional conditions (Ogundele 2018). The literature on the risk factors for behavioral problems in children has mainly focused on familial characteristics, as the predictors of behavioral problems. Psychologists have placed greater emphasis on child-parent relationships in recent decades. They argue that parental interactions can serve as a basis for a child's cognitive-emotional development and reduce the risk of developing mental health disorders. Mothers' parenting-related stress seems to be a major factor in the emergence of behavioral disorders in children with 
learning disabilities. It is a stressful experience to be the parent of a child with learning disabilities; the mothers of such children usually experience extensive stresses, especially of parental type (Hsiao 2018). The number of children with learning disabilities has exponentially increased over the past decades; therefore, parents are encountering the unique challenges of raising children (Moreau \& Waldie 2016). The mothers of such children may develop poor mental health and emotional disturbance (Ceballos et al. 2020). Numerous studies highlighted the relationship between parental stress and behavioral disorders in children (Shiralinia, Izadi, \& Aslani 2019; Roccella et al. 2019; Van Loon et al. 2015; Neece Green \& Baker 2012).

Furthermore, children's learning disabilities can reduce the parental acceptance of mothers. Parental acceptance is among the main components of the child-mother interaction model proposed by Bratton and Landreth (2006). The mother-child relationship can greatly enhance mothers' understanding and acceptance of the child. MotherChild interactions are central to pathological studies. This is because poor interactions can cause emotional and behavioral disorders in children (Khodabakhshi-koolaee \& Aghaei Malekabadi 2020). The literature supported the relationship between mother-child interactions and children's behavioral disorders (Savell et al. 2019; Oh et al. 2019; Satoorian, Tahmassian \& Ahmadi 2016).

Parental stress and difficulties in mother-child interaction can generate behavioral disorders in children by affecting mothers' mental health. In general, children's learning disabilities can cause multiple upbringing challenges for mothers (Piotrowska et al. 2017). Moreover, when the dreams of having a healthy child are lost, mothers may exhibit psychological reactions, such as shock, denial, depression, guilt, anger, sadness, anxiety, and embarrassment. These reactions affect the functioning of family members (Y1lmaz \& Kucuk Alemdar 2019; Kendig et al. 2017). Evidence suggests that, compared to the mothers of normal children, the mothers of children with behavioral disorders experience an unfavorable psychological status as well as high levels of stress and mental health issues (Webb \& Ayers 2019). Numerous studies have reported the relationship between mothers' mental health and children's behavioral disorders (Aghaei-Malekabadi et al. 2021; León-Del-Barco et al. 2019; Maiuolo, Dean \& Ciarrochi 2019; Pruitt, Rhoden \& Ekas 2018; Riahi, Amini \& Salehi Veisi 2012).

The mothers of students with learning disabilities usually report extensive negative consequences of psychological wellbeing problems as soon as they notice their child's conditions. Many of them have been immersed in the intense and recurring feelings of sadness, despair, and hopelessness from the distant past. The mothers of such children also experience confusion, loss, and hardship (Kuhn, Ford \& Dawalt 2018). Considering the essential role of mothers in maintaining the psychosocial balance of families and various issues faced by the mothers of students with learning disabilities, it is necessary to conduct further studies on such mothers and plan to solve their problems. Therefore, the present study aimed to investigate the relationship between parental stress, mother-child interaction, and the behavioral disorders of children mediated by mental health in the mothers of children with learning disabilities.

\section{Materials and Methods}

This was a descriptive and correlational study. The research population consisted of the mothers of elementary students with learning disabilities in Andimeshk City, Iran, in the academic year of 2020-2021. After obtaining permission from the officials of training centers for children with learning disabilities in Andimeshk City and briefing the mothers of such children on the research objectives and procedure, the research questionnaires were distributed among 235 mothers who accepted to participate in the study. They were recruited by convenience sampling method and provided a signed informed consent form. In total, 210 questionnaires were analyzed following the elimination of incomplete questionnaires. The inclusion criteria were having a child diagnosed with a learning disability by a psychologist, being $25-50$ years old, minimum literacy to understand the questionnaire items, and not being separated or divorced. The exclusion criteria of the study were unwillingness to continue the study and failure to complete the questionnaires.

The following instruments were employed to collect the required data:

The Child Behavior Checklist (CBCL): The parent version of this checklist was designed by Rutter in 1967. This checklist consists of 31 items and is used to assess the rate of behavioral disorders in children. The questionnaire is scored based on a 3-point Likert-type scale $(0,1, \& 2)$. The minimum and maximum scores obtainable on this checklist are 0 and 62, respectively. A higher score indicates a higher level of children's behavioral disorders. In this study, the total score of the test was used. The validity of this checklist has been evaluated as acceptable. Fombonne (1989) reported the reliability of this questionnaire equal to 0.75 based on Cronbach's alpha coefficient. Heydari et al. (2007) reported a Cron- 
bach's alpha coefficient of 0.85 for the whole Persian version of the questionnaire. In the present study, the reliability of the child behavior checklist was measured by Cronbach's alpha coefficient and equaled 0.79.

The Parental Stress Scale (PSS): The PSS, developed by Abidin in 1992, consists of 36 items that measure the significance of stress in the parent-child system. This scale has 3 subscales. The first subscale addresses parental distress (the first 12 questions) and measures the feelings of parenting stress over other personal stresses. The second subscale concerns the characteristics of a problematic child (the second 12 questions), suggesting the behaviors of children that make parenting easier or more difficult. Finally, the third subscale reflects dysfunctional parent-child interactions (the third 12 questions), which addresses the extent to which the child's behavior reinforces the parenting behavior. The items are scored on a 5-point Likert-type scale (from totally agree to totally disagree). A higher score indicates a higher level of parental stress. In this study, the total score of the questionnaire was used. Babakri,Tahmasebi and Amani (2018) reported a Cronbach's alpha coefficient of 0.89 for the whole scale. In the present study, Cronbach's alpha coefficient was measured as 0.80 for the whole scale.

The Child-Parent Relationship Scale (CPRS): This 33-item scale was developed by Pianta in 1994 to measure parents' perceptions of their relationships with their children. It has 3 subscales, including closeness (9 items), dependence (6 items), and conflict (18 items). The items are scored on a 5-point Likert-type scale (from totally disagree to totally agree). The total score of this scale is obtained from the sum of the scores of "closeness" as well as the inverse scores of "conflict" and "dependence". The total score on this scale was used for data analysis in this study. A higher score indicates a higher level of the child-parent relationship. Kabiri and Kalantari (2018) reported a Cronbach's alpha coefficient of 0.82 for the Persian version of the whole scale. In the present study, Cronbach's alpha coefficient was computed as 0.80 for the whole scale.

The Symptom Checklist (SCL-25): The Symptom Checklist (SCL-25) as a mental health questionnaire consists of 25 items designed by Dragatis and Zickelsurak in 1972. These items are rated on a 5-point Likert-type scale, ranging from 0 to 4 . The questionnaire consists of 9 subscales concerning psychiatric symptoms, including physical complaints; obsessional thoughts and acts; interpersonal sensitivity; anxiety; depression; paranoia and psychosis; phobia disorder and hostility, and aggression. The questionnaire probes the past week's experiences of different conditions. Along with the above-mentioned subscales, the items also mainly assess 3 dimensions, including General Severity Index (GSI), Positive Symptom Distress Index (PSDI), and Positive Symptom Total (PST). The minimum and maximum scores obtainable on this questionnaire are 0 and 100 , respectively. A higher score indicates a lower level of mental health. In this study, the total score of the test was used. Yousefi et al. (2019) reported a Cronbach's alpha coefficient of 0.85 for the Persian version of the questionnaire. In the present study, Cronbach's alpha coefficient was calculated as 0.82 for the questionnaire.

The path analysis was used to assess the proposed model. SPSS 25 and AMOS v. 24 were applied for analyzing the data.

\section{Results}

The findings related to demographic variables suggested that $71 \%$ of the study participants' age range was $27-39$ years, and $29 \%$ aged $40-48$ years. The mean \pm SD age of the research participants was $35.63 \pm 12.25$ years. Furthermore, most study participants $(52 \%)$ had a high school education. The collected data also indicated that $63.4 \%$ of the examined mothers were housewives and $36.6 \%$ of them were employed. Table 1 presents the mean, standard deviation, and Pearson correlation coefficient values of all explored variables. Figure 1 also shows the proposed model of behavioral disorders in children based on parental stress, mother-child interaction, and mother's mental health.

Based on Table 2, the Root Mean Square Error of Approximation (RMSEA) was equal to 0.054 ; thus, the primary model can be finalized without any corrections or changes. The final model is illustrated in Figure 2. The relevant results confirmed the model's goodness of fit.

Table 3 presents the results of estimating path coefficients for examining direct paths. Based on the collected results, there was a direct and significant relationship between parental stress and children's behavioral disorders $(\beta=0.321, \mathrm{P}=0.0001)$, as well as mother-child interactions and mental health $(\beta=0.255, \mathrm{P}=0.001)$ in the mothers of children with learning disabilities. There was a negative relationship between mother-child interaction and children's behavioral disorders $(\beta=-0.148$, $\mathrm{P}=0.019)$, as well as parental stress and mental health ( $\beta=-0.581, P=0.0001)$. Additionally, there was a reverse and significant relationship between mental health and child behavioral disorders $(\beta=-0.360, \mathrm{P}=0.0001)$ in the examined mothers of children with learning disabilities. 
Table 1. Mean, SD, and Pearson correlation coefficient values of the study variables

\begin{tabular}{|ccc|}
\hline Variable & Mean \pm SD & Pearson Correlation Coefficient \\
\hline Child behavioral disorders & $31.52 \pm 12.61$ & 1 \\
\hline Parental stress & $108.30 \pm 38.02$ & 0.594 \\
\hline Mother-child interaction & $97.56 \pm 24.30$ & -0.390 \\
\hline Mother-child interaction (closeness) & $25.99 \pm 7.75$ & -0.342 \\
\hline Mother-child interaction (dependence) & $18.46 \pm 5.16$ & -0.310 \\
\hline Mother-child interaction (conflict) & $53.10 \pm 16.72$ & -0.313 \\
\hline Mental health & $43.44 \pm 24.24$ & -0.629 \\
\hline
\end{tabular}

Client- Centered Nursing Care

The indirect path of parental stress to children's behavioral disorders was significant according to the mediating role of mental health $(\beta=0.069, \mathrm{P}=0.001)$. Moreover, the indirect path of mother-child interaction to children's behavioral disorders was significant through the mediating role of mental health $(\beta=-0.160, \mathrm{P}=0.001)$ (Table 4).

\section{Discussion}

The present study aimed to investigate the relationship between parental stress, mother-child interactions, and children's behavioral disorders with the mediating role of mental health in the mothers of children with learning disabilities. The obtained results signified that all direct paths were statistically significant. Indirect paths were also significant through the relationship between mental health and children's behavioral disorders. Accordingly, there was a direct and positive relationship between parental stress and behavioral disorders in these children. This finding was consistent with those of Shiralinia, Izadi and Aslani (2019) on the mediating roles of parenting stress, the quality of mother-child relationships, and mothers' mental health in the relationship between mindful parenting and children's behavioral problems. Van Loon et al. (2015) also evaluated factors promoting mental health in adolescents with a parent encountering mental illness. They stated that parental mental health plays a fundamental role in the health status of individuals and the whole society. The parent-child relationship is a combination of unique behaviors, feelings, and expectations that exist between parents and children; it involves quality time, physical affection, and verbal

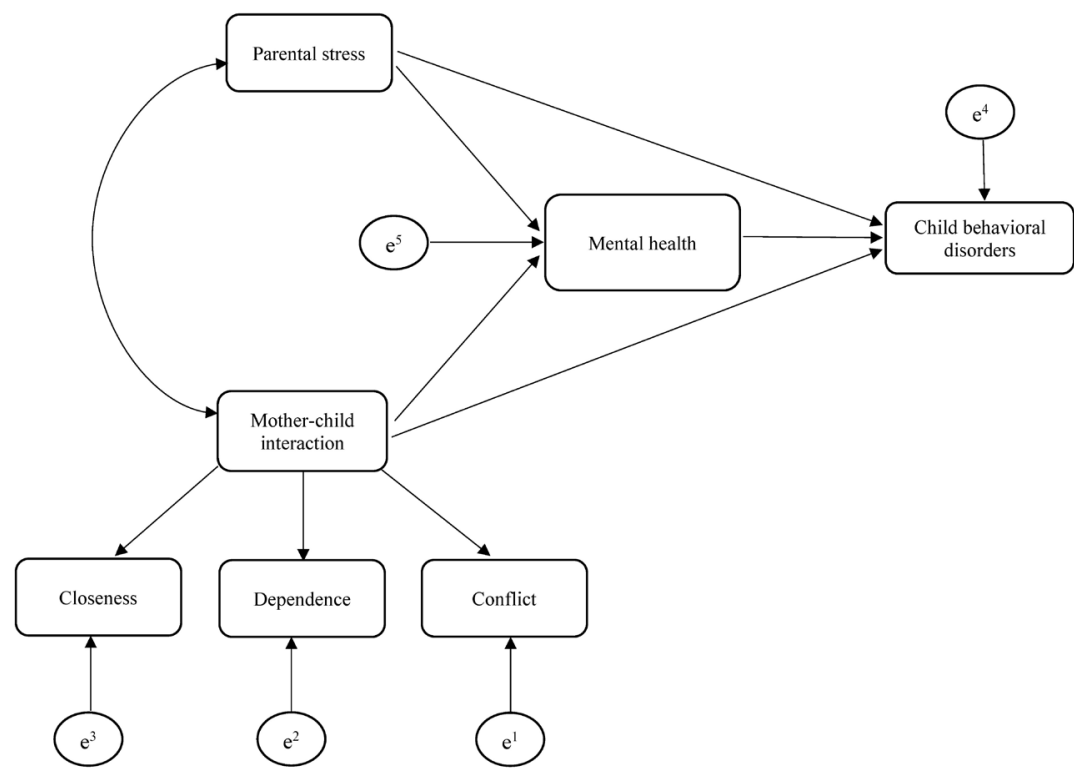

Client- Centered Nursing Car

Figure 1. The proposed model on the mediating role of mental health in the relationship between mother-child interaction, parental stress, and children's behavioral disorders 
Table 2. Proposed and final model fit indicators

\begin{tabular}{cccccccccc}
\hline Fit Indicators & $\chi^{2}$ & $\mathbf{d f}$ & $\left(\boldsymbol{\chi}^{2} / \mathbf{d f}\right)$ & IFI & GFI & TLI & CFI & NFI & RMSEA \\
\hline Proposed and final model & 12.95 & 6 & 2.15 & 0.97 & 0.89 & 0.92 & 0.97 & 0.99 & 0.054 \\
\hline
\end{tabular}

Client- Centered Nursing Car IFI: Incremental Fit Index; GFI: Goodness of Fit Index; TLI: Tucker Lewis Index; CFI: Comparative Fit Index; NFI: Normalized Fit Index; RMSEA: Root Mean Square Error of Approximation.

communication (Castro et al. 2015). The parent-child relationship is among the main factors affecting children's biopsychosocial development. Inefficient parenting styles and inappropriate parent-child interactions can cause communication problems in children; consequently, such conditions predispose them to disorders, such as anxiety, behavioral disorders, and psychological damage. Neece, Green and Baker (2012) argued that there is generally a mutual relationship between parental stress and children's behavioral problems. According to Keen et al. (2010), high levels of parental stress, especially in mothers, make them more prone to implementing inflexible, threatening, and aggressive parenting styles. This can negatively affect a child's development and cause them to exhibit further destructive behaviors.

Another study result determined a significant and reverse relationship between mother-child interactions and children's behavioral disorders. This finding was consistent with those of Satoorian, Tahmassian and Ahmadi (2016) on the role of parenting dimensions and childparent relationship in children's internalized and externalized behavioral problems. These findings were also in line with those of Savell et al. (2019) on the role of early discrimination experiences and the parent-child relationship in the development of disruptive behaviors in adolescence. In other words, mothers play a crucial role in the behavioral disorders of children. Based on the mother-child interaction model, more emotional awareness and higher self-regulatory capacity can help mothers experience less stress, have better interaction with their children, and adopt a more consistent parenting style. Siegel (2001) argues that the mother-child interaction model combines listening with complete attention. This is because mothers pay complete attention to their children and let them know that they are attentively listening to them. During direct interactions between parents and children, attentiveness can serve as an internal representation of parents and their supportive performance for children. This creates a responsive and accessible figure of parents for children that protect them from threats, contributes to the emergence of a secure attachment style, and improves the quality of parent-child relationships (Siegel 2001). Additionally, children's behavioral problems are rooted in negative mother-child interactions. The quality of the mother-child interaction and mothers' emotional intimacy are parenting factors that can predict anxiety and mood disorders in children.

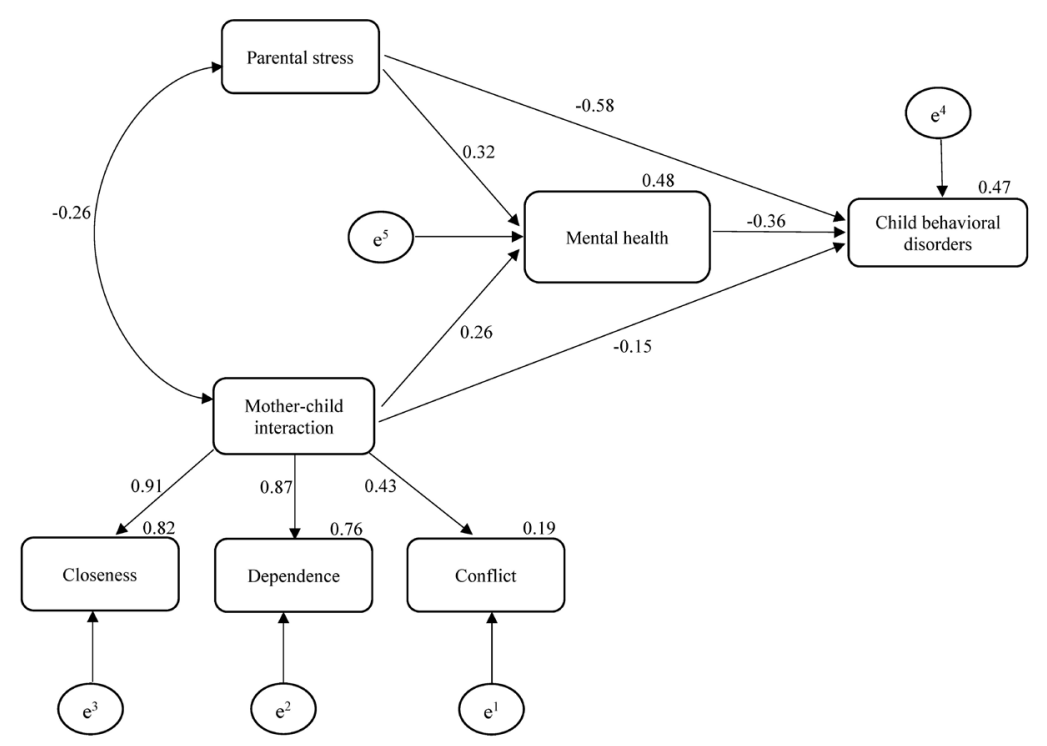

Client- Centered Nursing Care

Figure 2. The final model on the mediating role of mental health in the relationship between mother-child interaction, parental stress, and children's behavioral disorders 
Table 3. The path coefficients of direct effects between research variables in the final model

\begin{tabular}{cccc}
\hline & & The Final Model \\
& Path & $\boldsymbol{\beta}$ & $\mathbf{P}$ \\
\cline { 2 - 4 } Parental stress to child behavioral disorders & Path Type & 0.321 & 0.0001 \\
\hline Mother-Child interactions to child behavioral disorders & Direct & -0.148 & 0.019 \\
Parental stress to mental health & Direct & -0.581 & 0.0001 \\
\hline Mother-Child interactions to mental health & Direct & 0.255 & 0.0001 \\
\hline Mental health to child behavioral disorders & Direct & -0.360 & 0.0001 \\
\hline
\end{tabular}

Client- Centered Nursing Care

As a result, the increased quality of these two factors can solve children's internalized problems, like anxiety (Franz \& McKinney 2018). It seems that positive and intimate relationships involve understanding the underlying factors of a child's behavior and the ability to effectively respond to these behaviors; accordingly, it serves as a supporter and prevents anxiety and mood disorders.

The study findings also demonstrated a direct and negative relationship between mothers' mental health and behavioral disorders in the explored children with learning disabilities. Therefore, mothers' improved mental health is expected to reduce children's behavioral disorders. This finding was consistent with those of Riahi, Amini and Salehi Veisi (2012) on children's behavioral problems and their relationship with maternal mental health; as well as those of Pruitt, Rhoden and Ekas (2018) respecting the relationship between the broader autism phenotype, social relationships, and the mental health of mothers of children with autism spectrum disorders. Mental health generally refers to situations in which individuals appropriately respond to environmental and interpersonal requirements. One of the sources of stress for mothers is having a child with learning disabilities. Such children generate special stress in their parents, especially mothers. Major issues in the mothers of such children are accepting their child's disabilities, family's financial problems, and treating learning disabilities. Higher levels of parental stress are associated with poor family func- tioning, children's behavioral disorders, as well as poor correlation and cohesion. Stress reduction is related to problem-oriented coping strategies, optimal family functioning, and a sense of meaning in life; impairments in any of which can reduce the quality of the mother-child interaction and increase the risk of behavioral disorders in children (Riahi, Amini \& Salehi Veisi 2012). The increased awareness of mothers about their negative feelings and emotions, such as anxiety and stress, not only improves their mental health but also reduces behavioral disorders among children (Ganjiwale et al. 2016). Mothers require an optimal level of mental health as well as emotional and social wellbeing to be able to take care of and raise their children; failure to achieve this optimal level can disrupt the parent-child relationship. High levels of maternal anxiety, anger, and depression affect the quality of maternal care; therefore, such conditions impact the child's behaviors, either directly or indirectly (Ryan O'Farrell \& Ramchandani 2017).

The collected results also indicated that mental health played a mediating role in the relationship between parental stress and mother-child interactions. No similar finding was found in the literature in this regard. To explain this finding, it can be stated that positive motherchild interactions improve the mental health status of mothers and children. In other words, appropriate mother-child interactions improve the mental health of mothers and reduce behavioral disorders of children. The par-

Table 4. The Bootstrap method data for investigating indirect and intermediary paths

\begin{tabular}{ccccc}
\hline \multirow{2}{*}{$\begin{array}{c}\text { Predictor Variable } \\
\text { Parental stress }\end{array}$} & Mediating Variable & Criterion Variable & \multicolumn{2}{c}{ The Final Model } \\
\cline { 4 - 5 } & Mental health & Child behavioral disorders & 0.069 & 0.001 \\
\hline Mother-Child interactions & Mental health & Child behavioral disorders & -0.160 & 0.001 \\
\hline
\end{tabular}

Client- Centered Nursing Care 
ent-child relationship is among the main factors affecting the biopsychosocial development of children. This is because the quality of these relationships in the early years of childhood can underpin future cognitive, social, and emotional development in individuals. It is also effective in the formation of concepts, such as health and disease and the patterns of normal and abnormal behaviors. Inefficient parenting styles and inappropriate parentchild interactions can lead to communication problems in children and predispose them to conditions, such as anxiety, behavioral disorders, and psychological damage (Shokoohi-Yekta, Parand \& Dargahi 2016). MotherChild interactions help mothers to experience high levels of self-inhibition and adjustment, have positive attitudes towards their children and spouse, and effectively communicate with them in the face of environmental stress (Anderson\& van Ee 2018).

Studies have also revealed that the families of children with learning disabilities report high levels of conflict and low levels of cohesion. Moreover, a sense of parenting inadequacy may gradually affect other private parts of the lives and marital relationships of the mothers of these children over time (Gerstein \& Crnic 2018; Mohammed Almarwani et al. 2020). As a result, parents, especially the mothers of such children naturally encounter further problems. This highlights the importance of mother-child interactions and the management of negative emotions and feelings. This skill helps individuals to be aware of problems and stresses; find the right strategies to cope with them; consequently, reduce the stress level of themselves and their children. This can improve the mental health status of children and reduce their behavioral problems. Thus, mental health can effectively mediate the relationship between parental stress, motherchild interactions, and children's behavioral disorders. Most behavioral problems of children reflect complex interpersonal relationships between their family members, especially their parents. In other words, behavioral problems in children indicate inappropriate relationships between family members and are associated with the incorrect parenting methods of parents and their defective interactions with children (Goldberg \& Carlson 2014). The enhanced mother-child interactions are expected to improve the mental health of mothers and reduce behavioral disorders in children with learning disabilities.

The present study faced some limitations. The study population consisted of the mothers of students with learning disabilities in Andimeshk City, Iran; therefore, the study findings should be cautiously generalized to similar populations in other regions. Future studies are thus recommended to be conducted on similar popula- tions in other counties to increase the generalizability of the collected results. Additionally, the fathers of such students were not included in this study. Therefore, there is a need for conducting similar studies on the fathers of such students. Finally, it seems that training courses on parental stress and mother-child interactions may improve the mental health of mothers and reduce children's behavioral disorders.

\section{Conclusion}

The present study results suggested that the model proposed in this study was favorably fitted; thus, it can be considered as an essential step in identifying factors affecting the behavioral disorders of students with learning disabilities. It could also be used as an appropriate model for developing and designing programs to prevent the experienced stress of mothers and reduce their children's behavioral disorders. Some training courses are recommended to be held for psychotherapists and psychiatric nurses on parental stress and mother-child interactions to improve the mental health of mothers and reduce behavioral disorders in children.

\section{Ethical Considerations}

\section{Compliance with ethical guidelines}

The study was approved by the Ethics Committee of the Islamic Azad University, Ahvaz Branch (Code: IR.IAU.AHVAZ.REC.1399.099). All ethical principles are considered in this article. The participants were informed about the purpose of the research and its implementation stages and signed written informed consents before participation. They were also assured about the confidentiality of their information and were free to leave the study whenever they wished, and if desired, the research results would be available to them.

\section{Funding}

This article was extracted from the $\mathrm{PhD}$. dissertation of the first author at the Department of Psychology, Ahvaz Branch, Islamic Azad University, Ahvaz and received no financial support.

\section{Authors' contributions}

Conceptualization, supervision: Setareh Mohammadipour, Zahra Dasht Bozorgi; Methodology: Setareh Mohammadipour, Farzaneh Hooman; Investigation, writing-review \& editing: Farzaneh Hooman, Setareh Mohammadipour; Writin-original draft: Setareh Mo- 
hammadipour, Zahra Dasht Bozorgi; Funding acquisition, resources: Setareh Mohammadipour.

\section{Conflict of interest}

The authors declared no conflicts of interest.

\section{References}

Aghaei-Malekabadi, M., Khodabakhshi-Koolaee, A. \& Afkari, F., 2021. Effectiveness of the parent training programs of CALM and SPACE on the rumination and anxiety of mothers with a bully son. Journal of Client-centered Nursing Care, 7(2), p. 97-108. [DOI:10.32598/JCCNC.7.2.33.15]

Mohammed Almarwani, S., et al. 2020. The association between family cohesion and disability following blunt trauma: Findings from a level-I trauma center in Saudi Arabia. Injury Epidemiology, 7, p. 40. [DOI:10.1186/s40621-020-00271-0] [PMID] [PMCID]

Anderson, K. \& van Ee, E., 2018. Mothers and children exposed to intimate partner violence: A review of treatment interventions. International Journal of Environmental Research and Public Health, 15(9), p. 1955. [DOI:10.3390/ijerph15091955] [PMID] [PMCID]

Babakri, H., Tahmasebi, S. \& Amani, S., 2018. [Validation of the Parenting Stress Index (PSI) among mothers of preschool children in Tehran (Persian)]. Shenakht, 5(4), pp. 29-39. [DOI:10.29252/shenakht.5.4.29]

Benner, G. J., et al. 2013. Closing the achievement gap of youth with emotional and behavioral disorders through multi-tiered systems of support. Education and Treatment of Children, 36(3), pp. 15-29. [DOI:10.1353/etc.2013.0018]

Bratton, S. C. \& Landreth, G. L., 2006. Child Parent Relationship Therapy (CPRT) treatment manual: A 10-session filial therapy model for training parents. New York: Routledge. [DOI:10.4324/9780203956793]

Castro, V. L., et al. 2015. Parents' emotion-related beliefs, behaviors, and skills predict children's recognition of emotion. Infant and Child Development, 24(1), pp. 1-22. [DOI:10.1002/icd.1868] [PMID] [PMCID]

Ceballos, P. L., Bárcenas Jaimez, G. \& Bratton, S. C., 2020. Considerations for play therapy research with Latino populations. International Journal of Play Therapy, 29(4), pp. 213-22. [DOI:10.1037/pla0000122]

Fombonne, E., 1989. The child behaviour checklist and the rutter parental questionnaire: A comparison between two screening instruments. Psychological Medicine, 19(3), pp. 777-85. [DOI:10.1017/S0033291700024387] [PMID]

Franz, A. O. \& McKinney, C., 2018. Parental and child psychopathology: Moderated mediation by gender and parent-child relationship quality. Child Psychiatry and Human Development, 49(6), pp. 843-52. [DOI:10.1007/s10578-018-0801-0] [PMID]

Ganjiwale, D., et al. 2016. Quality of life and coping strategies of caregivers of children with physical and mental disabilities. Journal of Family Medicine and Primary Care, 5(2), pp. 343-8. [DOI:10.4103/2249-4863.192360] [PMID] [PMCID]
Gerstein, E. D. \& Crnic, K. A., 2018. Family interactions and developmental risk associated with early cognitive delay: Influences on children's behavioral competence. Journal of Clinical Child and Adolescent Psychology, 47(sup1), pp. S100-12. [DOI:10 .1080/15374416.2016.1157755] [PMID] [PMCID]

Goldberg, J. S. \& Carlson, M. J., 2014. Parents' relationship quality and children's behavior in stable married and cohabiting families. Journal of Marriage and the Family, 76(4), pp. 762-77. [DOI:10.1111/jomf.12120] [PMID] [PMCID]

Gow, M. A., Mostert, Y. \& Dreyer, L., 2020. The promise of equal education not kept: Specific learning disabilities - The invisible disability. African Journal of Disability, 9, p. 647. [DOI:10.4102/ ajod.v9i0.647] [PMID] [PMCID]

Heydari, J., et al. 2007. [Prevalence of behavior-emotional disorders and its associated factors among the primary school students of Sari township in 2006 (Persian)]. Journal of Mazandaran University of Medical Sciences, 16(56), pp. 91-100. http://jmums. mazums.ac.ir $/$ browse.php?a_id=183\&sid=1\&slc_lang=en

Holt, S. \& Yuill, N., 2017. Tablets for two: How dual tablets can facilitate other-awareness and communication in learning disabled children with Autism. International Journal of Child-Computer Interaction, 11, pp. 72-82. [DOI:10.1016/j.ijcci.2016.10.005]

Hsiao, Y. J., 2018. Parental stress in families of children with disabilities. Intervention in School and Clinic, 53(4), pp. 201-5. [DOI:10.1177/1053451217712956]

Kabiri, A. \& Kalantari, M., 2018. [The effectiveness of group positive parenting program on parental stress and mother-child interaction of mother of children with nocturnal enuresis (Persian)]. Knowledge E Research in Applied Psychology, 19(2), pp 115-24. [DOI:10.30486/JSRP.2018.543270]

Keen, D., et al. 2010. The effects of a parent-focused intervention for children with a recent diagnosis of autism spectrum disorder on parenting stress and competence. Research in Autism Spectrum Disorders, 4(2), pp. 229-41. [DOI:10.1016/j. rasd.2009.09.009]

Kendig, S., et al. 2017. Consensus bundle on maternal mental health: Perinatal depression and anxiety. Obstetrics and Gynecology, 129(3), pp. 422-30. [DOI:10.1097/AOG.0000000000001902] [PMID] [PMCID]

Khodabakhshi-Koolaee, A. \& Aghaei Malekabadi, M., 2020 Motherhood and home quarantine: Exploring the experiences of iranian mothers in caring for their children during the COVID-19 outbreak. Journal of Client-centered Nursing Care, 6(2), pp. 87-96. [DOI:10.32598/JCCNC.6.2.33.8]

Kivumbi, A., et al. 2019. Prevalence of behavioral disorders and attention deficit/hyperactive disorder among school going children in Southwestern Uganda. BMC Psychiatry, 19(1), p. 105. [DOI:10.1186/s12888-019-2069-8] [PMID] [PMCID]

Kohli, A., Sharma, S. \& Padhy, S. K., 2018. Specific learning disabilities: Issues that remain unanswered. Indian Journal of $P_{S y-}$ chological Medicine, 40(5), pp. 399-405. [DOI:10.4103/IJPSYM. IJPSYM_86_18] [PMID] [PMCID]

Kuhn, J., Ford, K. \& Dawalt, L. S., 2018. Brief report: Mapping systems of support and psychological well-being of mothers of adolescents with autism spectrum disorders. Journal of Autism and Developmental Disorders, 48(3), pp. 940-6. [DOI:10.1007/ s10803-017-3381-0] [PMID]

León-Del-Barco, B., et al. 2019. Parental psychological control and emotional and behavioral disorders among Spanish adolescents. International Journal of Environmental Research and Pub- 
lic Health, 16(3), p. 507. [DOI:10.3390/ijerph16030507] [PMID] [PMCID]

Maiuolo, M., Deane, F. P. \& Ciarrochi, J., 2019. Parental authoritativeness, social support and help-seeking for mental health problems in adolescents. Journal of Youth and Adolescence, 48(6), pp. 1056-67. [DOI:10.1007/s10964-019-00994-4] [PMID]

Moreau, D. \& Waldie, K. E., 2016. Developmental learning disorders: From generic interventions to individualized remediation. Frontiers in Psychology, 6, p. 2053. [DOI:10.3389/ fpsyg.2015.02053] [PMID] [PMCID]

Neece, C. L., Green, S. A. \& Baker, B. L., 2012. Parenting stress and child behavior problems: A transactional relationship across time. American Journal on Intellectual and Developmental Disabilities, 117(1), pp. 48-66. [DOI:10.1352/1944-7558117.1.48] [PMID] [PMCID]

Ogundele M. O., 2018. Behavioural and emotional disorders in childhood: A brief overview for paediatricians. World Journal of Clinical Pediatrics, 7(1), pp. 9-26. [DOI:10.5409/wjcp.v7.i1.9] [PMID] [PMCID]

Oh, A., et al. 2019. Exploring relationship among child maltreatment experience in childhood and behavior problems as young adults: Role of social support among college students in Hong Kong. International Social Work, 62(2), pp. 1011-24. [DOI:10.1177/0020872818762718]

Panicker, A. S. \& Chelliah, A., 2016. Resilience and stress in children and adolescents with specific learning disability. Journal of the Canadian Academy of Child and Adolescent Psychiatry, 25(1), pp. 17-23. [PMID] [PMCID]

Piotrowska, P. J., et al. 2017. Mothers, fathers, and parental systems: a conceptual model of parental engagement in programmes for child mental health-Connect, Attend, Participate, Enact (CAPE). Clinical Child and Family Psychology Review, 20(2), pp. 146-61. [DOI:10.1007/s10567-016-0219-9] [PMID] [PMCID]

Pruitt, M. M., Rhoden, M. \& Ekas, N. V., 2018. Relationship between the broad autism phenotype, social relationships and mental health for mothers of children with autism spectrum disorder. Autism: The International Journal of Research and Practice, 22(2), pp. 171-80. [DOI:10.1177/1362361316669621] [PMID]

Riahi, F., Amini, F. \& Salehi Veisi, M., 2012. The children's behavioral problems and their relationship with maternal mental health. Journal of Jahrom University of Medical Sciences, 10(1), pp. 46-52. [DOI:10.29252/jmj.10.1.46]

Roccella, M., et al. 2019. Parental stress and parental ratings of behavioral problems of enuretic children. Frontiers in Neurology 10, p. 1054. [DOI:10.3389/fneur.2019.01054] [PMID] [PMCID]

Ryan, R., O'Farrelly, C. \& Ramchandani, P., 2017. Parenting and child mental health. London Journal of Primary Care, 9(6), pp. 86-94. [DOI:10.1080/17571472.2017.1361630] [PMID] [PMCID]

Sahu, A., et al. 2018. Perception of families of children with specific learning disorder: An exploratory study. Indian Journal of Psychological Medicine, 40(5), pp 406-13. [DOI:10.4103/IJPSYM. IJPSYM_148_18] [PMID] [PMCID]

Satoorian, A., Tahmassian, K. \& Ahmadi, M., 2016. [The role of parenting dimensions and child-parent relationship in children's internalized and externalized behavioral problems
(Persian)]. Journal of Family Research, 12(4), pp. 683-705. https://jfr.sbu.ac.ir/article_97463.html?lang=en

Savell, S. M., et al. 2019. Considering the role of early discrimination experiences and the parent-child relationship in the development of disruptive behaviors in adolescence. Infant Mental Health Journal, 40(1), pp. 98-112. [DOI:10.1002/imhj.21752] [PMID] [PMCID]

Shiralinia, K., Izadi, M. \& Aslani, K., 2019. [The role of mediators of parenting stress, the quality of mother-child relationship and mental health of mother in the relationship between mindful parenting and behavioral problems of children (Persian)]. Counseling Culture and Psycotherapy, 10(38), pp. 135-46. [DOI:10.22054/QCCPC.2019.36302.1989]

Shokoohi-Yekta, M., Parand, A. \& Dargahi, M., 2016. [Familybased preventive interventions: Effects on parent-child relationship and parenting styles (Persian)]. Journal of Child Mental Health, 3(2), pp. 55-63. http://childmentalhealth.ir/article1-64-en.html

Siegel, D. J., 2001. Toward an interpersonal neurobiology of the developing mind: Attachment relationships, "mindsight," and neural integration. Infant Mental Health Journal, 22(1-2), pp. 6794. [DOI:10.1002/1097-0355(200101/04)22:13.0.CO;2-G]

Van Loon, L. M. A., et al. 2015. Factors promoting mental health of adolescents who have a parent with mental illness: A longitudinal study. Child \& Youth Care Forum, 44(6), pp. 777-99. [DOI:10.1007/s10566-015-9304-3] [PMID] [PMCID]

Vidyadharan, V. \& Tharayil, H. M., 2019. Learning disorder or learning disability: Time to rethink. Indian Journal of Psychological Medicine, 41(3), pp. 276-8. [DOI:10.4103/IJPSYM.IJPSYM_371_18] [PMID] [PMCID]

Webb, R. \& Ayers, S., 2019. Postnatal mental health and mothers' processing of infant emotion: an eye-tracking study. Anxiety, Stress, and Coping, 32(5), pp. 484-97. [DOI:10.1080/1061580 6.2019.1620215] [PMID]

Yılmaz, G. \& Kucuk Alemdar, D., 2019. Sources of anxiety and satisfaction level of the mothers whose children hospitalized for acute reasons. Journal of Client-centered Nursing Care, 5(1), pp. 63-70. [DOI:10.32598/jccnc.5.1.65]

Yousefi, F., et al. 2019. [Causal relationship between lifestyle and cognitive flexibility with mental health of exceptional children's mothers with mediating role of negative thinking control (Persian)]. Empowering Exceptional Children, 10(4), pp 61-73. [DOI:10.22034/CECIRANJ.2019.201486.1271] 